\title{
Atividade fitotóxica de Serjania lethalis sobre a germinação e crescimento de Panicum maximum
}

\author{
Viviane de Cassia Pereira * \\ Patrícia Umeda Grisi \\ Pavel Dodonov \\ Simoni Anese \\ Leonardo Toffano \\ Sonia Cristina Juliano Gualtieri \\ Universidade Federal de São Carlos, Campus São Carlos \\ Rodovia Washington Luís, km 235, SP-310, CEP 13565-905, São Carlos $\square$ SP, Brasil \\ * Autor para correspondência \\ vivicpereira@gmail.com
}

Submetido em 18/06/2013

Aceito para publicação em 18/12/2013

\section{Resumo}

Este artigo analisa a atividade fitotóxica de extratos aquosos de folhas jovens e maduras de Serjania lethalis A. St. -Hil. sobre a germinação e o crescimento de sementes de Panicum maximum Jacq. Foram preparados extratos aquosos nas concentrações de 2,5, 5,0, 7,5 e 10\% a partir de folhas secas e água destilada. A porcentagem de germinação, velocidade de germinação e sincronia foram afetadas negativamente pelos dois extratos. Os extratos exibiram fitotoxicidade e reduziram o crescimento de plântulas, e esses efeitos são dependentes da concentração. As diferentes concentrações dos extratos provocaram mudanças significativas no processo de germinação e crescimento de plântulas de P. maximum, em alguns casos variando devido ao estágio de maturação foliar, porém, não diferindo entre si para maioria das variáveis analisadas.

Palavras-chave: Extratos aquosos; Fitotoxicidade; Serjania lethalis

\section{Abstract}

Phytotoxic activity of Serjania lethalis on the germination and growth of Panicum maximum. This article analyzes the phytotoxic activity of aqueous extracts from young and mature leaves of Serjania lethalis A. St.-Hil. on the germination and growth of Panicum maximum Jacq. seeds. We prepared aqueous extracts at concentrations of 2.5, 5.0,7.5, and $10 \%$ from dry leaves and distilled water. Germination percentage, germination speed, and synchronicity were negatively affected by both extracts. The extracts exhibited phytotoxicity and reduced seedlings' growth, and these effects depend on concentration. The different extract concentrations caused significant changes in the germination process and the growth of $P$. maximum seedlings, in some cases varying due to leaf maturation stage, but they did not differ from each other for most variables under analysis.

Key words: Aqueous extracts; Phytotoxicity; Serjania lethalis 


\section{Introdução}

As plantas possuem compostos oriundos do metabolismo secundário, os chamados aleloquímicos (SILVA et al., 2011), presentes nas folhas, raiz, caule e frutos (WEIR et al., 2004) e que possuem a função de defesa contra ataques de patógenos, herbivoria e predação (WALLER et al., 1999). Ultimamente, estes compostos do metabolismo secundário têm sido utilizados como promissores herbicidas naturais no controle de plantas daninhas (GRISI et al., 2011; SILVA et al., 2011), podendo ser empregados com sucesso na agricultura (SILVA, 2012).

As plantas daninhas estão entre os principais fatores que limitam o crescimento de espécies cultivadas (PITELLI, 1985; FAO, 2009; LUZ et al., 2010). Isto se dá pela competição com outras plantas por fatores que promovem o crescimento (DIAS FILHO, 1998), principalmente espaçamento, água, luz e nutrientes (BELOTTO, 1997). Um exemplo é o Panicum maximum Jacq. (capim-colonião), forrageira da família Poaceae que é conhecida como uma das plantas infestantes mais importantes em áreas canavieiras e de reflorestamentos, principalmente devido a sua elevada agressividade, intensa capacidade de produção e longevidade de sementes (DA COSTA et al., 2002).

Herbicidas sintéticos são amplamente utilizados no controle de plantas daninhas (FREITAS et al., 2004), inclusive no controle do P. maximum (ALVES et al., 2002). No entanto, estes herbicidas apresentam problemas quando comparados com os naturais, devido aos impactos causados no ambiente (SOUZA FILHO et al., 2006). Alguns representantes da família Sapindaceae, o gênero Sapindus, por exemplo, apresentaram atividade fitotóxica ao alterar o processo germinativo e provocar alterações morfológicas em hortaliças e plantas daninhas (GRISI et al., 2012).

Serjania lethalis A. St.-Hil., uma liana tipicamente encontrada no cerrado brasileiro (FERNANDES; NEGREIROS, 2001) é outra espécie da família Sapindaceae que apresenta-se promissora para estudos de fitotoxicidade. Grisi et al. (2013) avaliaram o potencial fitotóxico de extratos etanólicos de folhas e caules de $S$. lethalis sobre a germinação de diásporos e crescimento de plântulas das espécies daninhas amendoim-bravo (Euphorbia heterophylla L.) e capim-arroz (Echinocloa crus-galli (L.) P. Beauv.). Os resultados apontam que os extratos etanólicos das folhas e caule exerceram atividade inibitória no processo de germinação e crescimento de plântulas das espécies alvo estudadas. Pires (2008) registrou o potencial moluscicida desta espécie, Napolitano et al. (2005) discutiram a sua atividade farmacológica. Serjania lethalis possui ampla distribuição em todas as regiões do Brasil, na Bolívia e no Peru (ACEVEDORODRÍGUEZ, 1990), assim, por se tratar de uma espécie abundante no cerrado e amplamente distribuída no Brasil, decidiu-se testar o potencial fitotóxico dos extratos aquosos de suas folhas jovens e maduras, a fim de comprovar seu potencial fitotóxico e comparar os efeitos exercidos por extratos provenientes de dois estágios de maturação diferentes.

Assim, os objetivos deste trabalho foram avaliar o efeito de diferentes concentrações de extratos aquosos de folhas jovens e maduras de $S$. lethalis sobre a germinação e crescimento de $P$. maximum.

\section{Material e Métodos}

Folhas, jovens e maduras, de $S$. lethalis foram coletadas em uma área de cerrado sensu stricto no município de São Carlos - SP (22 02 'S e $\left.47^{\circ} 52^{\prime} \mathrm{W}\right)$, em setembro de 2011. Foram consideradas jovens as folhas que apresentaram coloração verde clara e textura membranácea e maduras as folhas com coloração verde escura e textura coriácea (GRISI et al., 2012).

As folhas foram secas em estufa de circulação forçada à temperatura constante de $40^{\circ} \mathrm{C}$ durante cinco dias e trituradas em moinho industrial. $\mathrm{O}$ extrato aquoso foi preparado a partir de $100 \mathrm{~g}$ de material vegetal seco para $1 \mathrm{~L}$ de água destilada e deixado em repouso durante $24 \mathrm{~h}$ a $4^{\circ} \mathrm{C}$. Em seguida, foi filtrado utilizando-se uma bomba de alto vácuo com funil de Buchner forrado com papel-filtro, segundo recomendações de Gatti et al. (2004). Assim, foi obtido o extrato na concentração $10 \%$. Posteriormente, foram feitas diluições para 2,5; 5,0 e 7,5\%. O pH dos extratos de folhas jovens e maduras na concentração $10 \%$ foi medido com o pHmetro Analion 
e a concentração molar, com o osmômetro automático ( $\mu$ Osmotte).

Os extratos aquosos, de folhas jovens e maduras, foram aplicados sobre sementes de $P$. maximum para avaliar o processo de germinação quando comparados com o tratamento controle. Foram utilizadas quatro repetições com 30 sementes, distribuídas em placas de Petri de $9 \mathrm{~cm}$ com duas folhas de papel-filtro contendo 5 $\mathrm{mL}$ de extratos, de folhas jovens ou maduras, ou controle (água destilada). As placas foram cobertas com papel filme, com o propósito de manter a umidade no interior da placa (MARASCHIN-SILVA; ÁQUILA, 2006). O experimento foi conduzido em câmara de germinação a $20-30{ }^{\circ} \mathrm{C}$ e fotoperíodo de $16-8 \mathrm{~h}$ (TOMAZ et al., 2010). As leituras foram realizadas a cada $24 \mathrm{~h}$, sendo considerada germinada a semente que apresentava protrusão mínima do embrião. Ao final, foram avaliados a germinabilidade, o tempo médio, velocidade média e a sincronia de germinação, de acordo com Ranal e Santana (2006).

Paralelamente foi realizado um bioensaio para verificar o efeito osmótico dos extratos. Soluções de polietilenoglicol (PEG) 6000 a -0,14 e -0,09 MPa, além do controle, foram utilizadas para o bioensaio de germinação com sementes de $P$. maximum. A metodologia adotada foi a mesma para o bioensaio com o extrato vegetal.

Para avaliar o crescimento das plântulas em contato com os extratos, sementes de $P$. maximum foram pré-germinadas em $8 \mathrm{~mL}$ de água destilada. Quando apresentaram $3 \mathrm{~mm}$ de radícula foram transferidas para caixas plásticas transparentes $(12 \times 8 \times 5 \mathrm{~cm})$ forradas com papel filtro umedecido com $8 \mathrm{~mL}$ de extrato nas mesmas concentrações adotadas no teste de germinação. Foram utilizadas quatro repetições de dez plântulas por tratamento incluindo o controle (água destilada). As caixas foram mantidas durante sete dias em câmara de germinação a $20-30{ }^{\circ} \mathrm{C}$ e fotoperíodo de 16-8 h (TOMAZ et al., 2010). Após este período foram medidos, com o auxílio de um paquímetro digital, o comprimento da parte aérea e da raiz primária.

Os dados obtidos para cada uma das características avaliadas foram submetidos aos testes de normalidade
(Shapiro-Wilk) e homogeneidade (Levene). Quando essas duas pressuposições foram atendidas, foi aplicada a análise de variância (ANOVA), seguida pelo teste de Tukey a 0,05 de significância. Procedeu-se à regressão linear ou quadrática quando o resultado da ANOVA foi significativo. $\mathrm{O}$ ajuste do modelo foi testado a 0,05 de significância e avaliado pelo seu coeficiente de determinação $\left(\mathrm{R}^{2}\right)$. As variáveis que não apresentaram diferenças significativas entre os tratamentos foram representadas nas figuras com os valores médios e seus respectivos desvios padrão.

Para comparação dos efeitos ocasionados pelas folhas jovens e maduras, foi realizada análise conjunta para as características em que a razão entre o maior e o menor quadrado médio residual não foi superior a sete (PIMENTEL-GOMES, 1990).

\section{Resultados e Discussão}

Os extratos aquosos de folhas jovens e maduras de $S$. lethalis inibiram significativamente o processo de germinação das sementes de capim-colonião. Para essas unidades de dispersão semeadas com extrato de folhas jovens, observou-se decréscimo linear na germinabilidade $(3,53 \%$ para cada adição de $0,01 \mathrm{~g} / \mathrm{mL}$ de extrato); enquanto, o tempo e a velocidade média de germinação atingiram seus valores mínimo (3,82 dias) e máximo $\left(0,2594\right.$ dias $\left.^{-1}\right)$ nas concentrações estimadas de 2,7 e $2,6 \%$, respectivamente. $\mathrm{O}$ efeito do extrato de folhas jovens foi significativo para a sincronia, porém, seus valores não se ajustaram aos modelos de regressão; a menor sincronia foi registrada partir da concentração $5 \%$ (Figura 1). O extrato de folhas maduras promoveu aumento linear no tempo médio de germinação $(0,1940$ dias para cada adição de $0,01 \mathrm{~g} / \mathrm{mL}$ de extrato) e, como consequência, houve decréscimo linear na velocidade média e na sincronia de germinação $\left(0,0095 \operatorname{dias}^{-1} \mathrm{e}\right.$ 0,0145 para cada $0,01 \mathrm{~g} / \mathrm{mL}$ de extrato adicionado). A germinabilidade das sementes de capim-colonião foi mínima $(72,50 \%)$ na concentração $10 \%$ de extrato de folhas maduras (Figura 1).

Os extratos de folhas jovens e maduras de $S$. lethalis exerceram efeito inibitório significativo sobre o crescimento radicular de capim-colonião. Sob a ação do 
FIGURA 1: Germinabilidade, tempo e velocidade média de germinação e sincronia de germinação das sementes de capim-colonião submetido à ação do extrato de folhas jovens e maduras de $S$. lethalis, em diferentes concentrações.

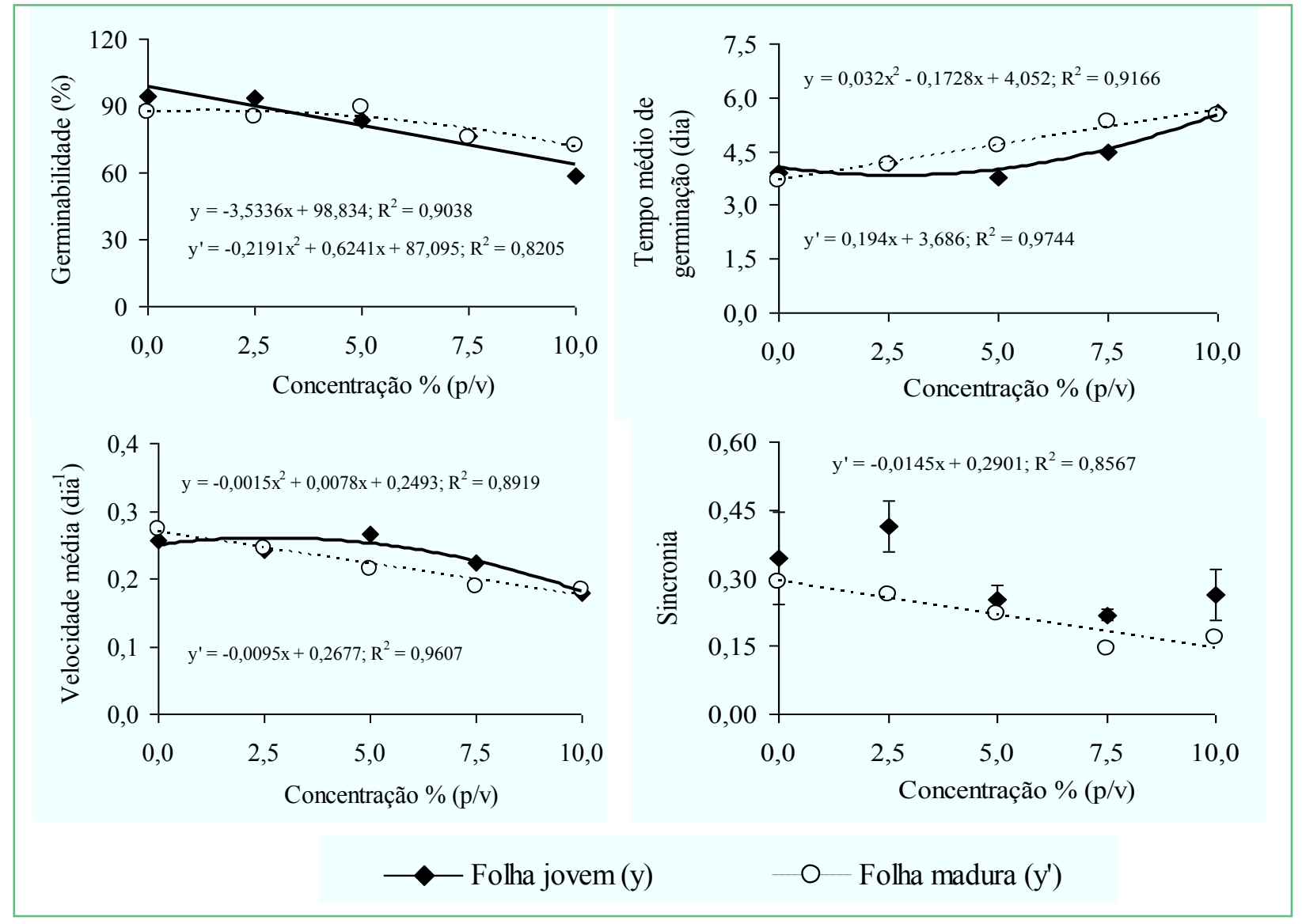

FIGURA 2: Crescimento radicular e da parte aérea de capim-colonião submetido à ação do extrato de folhas jovens e maduras de $S$. lethalis, em diferentes concentrações.

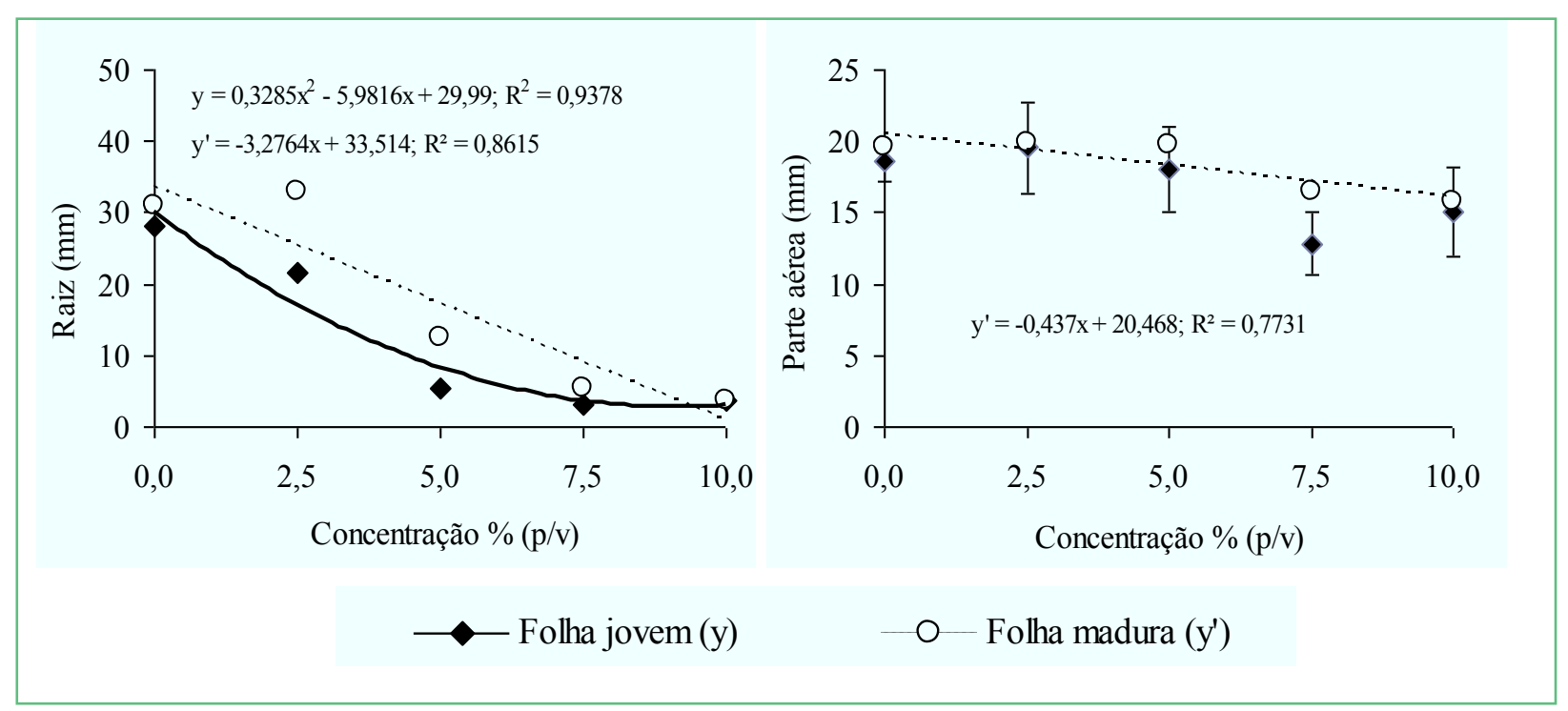


extrato de folhas maduras, verificou-se decréscimo linear no comprimento radicular de 3,27 mm para cada adição de $0,01 \mathrm{~g} / \mathrm{mL}$ de extrato, enquanto que, sob o efeito do extrato de folhas jovens, as plântulas apresentaram comprimento mínimo $(2,73 \mathrm{~mm})$ na concentração estimada de 9,11\% (Figura 2). O crescimento da parte aérea foi afetado significativamente pelo extrato de folhas maduras, com decréscimo linear de $0,43 \mathrm{~mm}$ para cada adição de $0,01 \mathrm{~g} / \mathrm{mL}$ de extrato. Os valores de crescimento da parte aérea, sob a influência do extrato de folhas jovens, não apresentaram ajustes aos modelos de regressão, porém na concentração de 7,5 \% foi registrado o menor valor de crescimento (Figura 2).

Comparando o efeito dos diferentes estágios de maturação das folhas de $S$. lethalis, verificou-se que ambos os extratos afetaram de maneira similar a germinabilidade e o crescimento da parte aérea das plântulas de capim-colonião. Para as demais variáveis do processo de germinação, o extrato de folhas maduras exerceu maior atividade inibitória; em contrapartida, o crescimento radicular foi mais afetado pelo extrato de folhas jovens (Tabela 1).

Com relação às características físico-químicas dos extratos de folhas jovens e maduras de $S$. lethalis, os valores de $\mathrm{pH}$ variaram entre 6,10 e 6,50, respectivamente, verificando-se reduzida variação entre os valores. Considerando-se que a germinação e o desenvolvimento de plântulas são afetados negativamente em condições de extrema acidez ou extrema alcalinidade (SOUZAFILHO et al., 1996), pode-se dizer que o pH desses extratos não interferiu nestes processos.
Os valores de potencial osmótico $(0,1$ e 0,09 para folhas jovens e maduras, respectivamente) e $\mathrm{pH}$ estiveram dentro dos limites de não-interferência no processo germinativo (SOUZA-FILHO et al., 1996). A porcentagem, velocidade e sincronia do processo germinativo de sementes que estiveram sob o efeito de soluções de polietilenoglicol (PEG) 6000 a -0,14 e -0,09 MPa não apresentaram diferenças estatísticas significativas quando comparadas com o tratamento controle. Grisi et al. (2011) constataram que o potencial osmótico de -0,18MPa encontrado em extratos de frutos de Sapindus saponaria L. (Sapindaceae) não interferiu no processo de germinação de sementes e na morfologia de plantas daninhas e de hortaliças. Desta forma, assumiu-se que todos os resultados obtidos foram devidos aos efeitos provocados pelos extratos.

Extratos aquosos de folhas jovens e maduras de $S$ saponaria reduziram a germinação de diásporos e o comprimento de plântulas das espécies daninhas capimarroz e corda-de-viola, sendo os efeitos causados pelo extrato de folhas jovens similares aos provocados pelo herbicida nicosulfuron, sugerindo a potencialidade fitotóxica destes extratos (GRISI et al., 2012).

Tanto o extrato de folhas jovens quanto o de folhas maduras apresentou efeito inibitório na germinação das sementes e no crescimento das plântulas de P. maximum. Sabe-se que alterações na velocidade de germinação podem ter consequências ecológicas, pois sementes que germinam mais lentamente podem dar origem a plântulas com tamanho reduzido (JEFFERSON; PENNACHIO, 2003).

TABELA 1: Germinação e crescimento de plântulas de capim-colonião submetidas à ação extrato das folhas jovens e maduras de S. lethalis.

\begin{tabular}{lcc}
\hline \multicolumn{1}{c}{ Variáveis (unidades) } & \multicolumn{2}{c}{ Extrato aquoso } \\
\cline { 2 - 3 } & Folha jovem & Folha madura \\
\hline G: germinabilidade $(\%)$ & $81,17 \mathrm{a}$ & $82,00 \mathrm{a}$ \\
$\overline{\mathrm{t}}$ : tempo médio de germinação (dia) & $4,39 \mathrm{a}$ & $4,66 \mathrm{~b}$ \\
$\bar{v}$ : velocidade média de germinação $\left(\mathrm{dia}^{-1}\right)$ & $0,0233 \mathrm{a}$ & $0,0220 \mathrm{~b}$ \\
$Z$ : sincronia & $0,2986 \mathrm{a}$ & $0,2183 \mathrm{~b}$ \\
Comprimento da parte aérea $(\mathrm{mm})$ & $16,81 \mathrm{a}$ & $18,28 \mathrm{a}$ \\
Comprimento da raiz $(\mathrm{mm})$ & $12,40 \mathrm{~b}$ & $17,57 \mathrm{a}$ \\
\hline
\end{tabular}

Médias seguidas por letras iguais na linha não diferem entre si pelos testes de Tukey a 0,05 de probabilidade. 
Os aleloquímicos provocam alterações bioquímicas e fisiológicas que afetam negativamente o crescimento e desenvolvimento das plântulas (WEIR et al., 2004). A interferência dos aleloquímicos ocorre com frequência na inibição da fotossíntese, respiração, permeabilidade da membrana celular e inibição da mitose, afetando todo o desenvolvimento da planta (GNIAZDOWSKA; BOGATEK, 2005). As raízes são os órgãos mais sensíveis à ação dos extratos (CHON et al., 2000), pois estão em contato direto com os aleloquímicos ali presentes (CHUNG et al., 2001). Extratos etanólicos de raiz e caule de $S$. lethalis também foram responsáveis pela atividade inibitória no processo de germinação e no crescimento das plântulas de capim-arroz e amendoim-bravo, com efeito dependente da concentração (GRISI et al., 2013).

Uma hipótese que pode ser responsável pelas alterações no crescimento das plântulas e nos parâmetros de germinação é a presença de saponinas, uma classe de compostos do metabolismo secundário característica da família Sapindaceae (MURGU; RODRIGUES-FILHO, 2006), estas possuem efeitos reguladores do crescimento de plântulas (OHARA; OHIRA, 2003). Contudo, a presença de saponinas em folhas de $S$. lethalis ainda precisa ser investigada. Nesse sentido, a presente pesquisa constitui uma etapa inicial para purificação e caracterização dos compostos responsáveis pelas atividades fitotóxicas ocasionadas pelas folhas jovens e maduras de S. lethalis. A identificação dessas fitotoxinas poderá oferecer perspectivas para indicação dessa espécie como uma planta doadora de compostos que possam atuar como herbicidas naturais.

Com base nos resultados conclui-se que as diferentes concentrações dos extratos provocaram mudanças significativas no processo de germinação e crescimento de plântulas de $P$. maximum, em alguns casos variando devido ao estágio de maturação foliar, porém não diferindo entre si para maioria das variáveis analisadas.

\section{Agradecimentos}

Os autores agradecem às agências de fomento à pesquisa CAPES, CNPq e FAPESP.

\section{Referências}

ACEVEDO-RODRÍGUEZ, P. Distributional patterns in Brazilian Serjania (Sapindaceae). Acta Botanica Brasilica, Feira de Santana, v. 4, n. 1, p. 69-82, 1990.

ALVES, E.; MARTINS, D.; SOUZA, F. H. D. Seletividade de herbicidas pré-emergentes para gramíneas forrageiras tropicais. Planta Daninha, Viçosa, v. 20, n. 3, p. 457-464, 2002.

BELOTTO, E. E. Controle de plantas daninhas em pastagens. In: SIMPÓSIO SOBRE HERBICIDAS E PLANTAS DANINHAS, 1, 1997, Dourados. Resumos... Dourados: EMBRAPA. 1997. p. 118130.

CHON, S. U.; COUTTS, J. H.; NELSON, C. J. Effects of light, growth media, and seedling orientation on bioassays of alfalfa autotoxicity. Agronomy Journal, Madison, v. 92, p. 715-720, 2000 .

CHUNG, I. M.; AHN, J. K.; YUN, S. J. Assessment of allelopathic potential of barnyard grass (Echinochloa crus-gall) on rice (Oriza sativa L.) cultivars. Crop Protection, Guildford, v. 20, n. 10, p. 921-928, 2001.

DA COSTA, E. A. D.; MATALlO, M. B.; CARVALHO, J. C.; ROZANSKI, A. Eficiência de nova formulação do herbicida oxyfluorfen no controle de plantas daninhas em área de Pinus caribea morelet var. hondurensis barr. et Golf. Revista Árvore, Viçosa, v. 26, p. 683-689, 2002.

DIAS FILHO, M. B. Pastagens cultivadas na Amazônia oriental brasileira: processos e causas de degradação e estratégias de recuperação. In: DIAS, L. E.; MELLO, J. W. V. (Ed.). Recuperação de áreas degradadas. Viçosa: DSO-UFV/SOBRADE, 1998. p. $135-147$

FAO. Food and Agriculture Organization oh the United Nations. 2009. Disponível em: <http://www.fao.org/news/story/ en/item/29402/icode/>. Acesso em: 21 nov. 2012.

FREITAS, S. P.; OLIVEIRA, A. R.; FREITAS, S. J.; SOARES, L. M. S. Controle químico de Rottboellia exaltata em cana-de-açúcar. Planta Daninha, Viçosa, v. 22, n. 3, p. 461-466, 2004.

FERNANDES, G. W.; NEGREIROS, D. The occurrence and effectiveness of hypersensitive reaction against galling herbivores across host taxa. Ecological Entomology, London, v. 26, n. 1, p. 46-55, 2001

GNIAZDOWSKA, A.; BOGATEK, R. Allelopathic in ter ac tions be tween plants. Multi site ac tion of allelochemicals. Acta Physiologiae Plantarum, Warszawa, v. 27, n. 3B, p. 395-407, 2005.

GATTI, A. B.; PEREZ, S. C. J. G. A.; LIMA, M. I. S. Atividade alelopática de extratos aquosos de Aristolochia esperanzae $\mathrm{O}$. Kuntze na germinação e no crescimento de Lactuca sativa L. e Raphanus sativus L. Acta Botanica Brasilica, Feira de Santana, v. 18, n. 3, p. 459-472, 2004

GRISI, P. U.; GUALTIERI, S. C. J.; RANAL, M. A.; SANTANA, D. G. Efeito alelopático do fruto de Sapindus saponaria na germinação e na morfologia de plântulas daninhas e de hortaliças. Planta Daninha, Viçosa, v. 29, n. 2, p. 311-322, 2011.

GRISI, P. U.; RANAL, M. A; GUALTIERI, S. C. J.; SANTANA, D. Allelopathic potential of Sapindus saponaria L. leaves in the control of weeds. Acta Scientiarum Agronomy, Maringá, v. 34, n. 1, p. 1-9, 2012. 
GRISI, P. U.; GUALTIERI, S. C. J.; ANESE, S.; PEREIRA, V. C., FORIM, M. R. Efeito do extrato etanólico de Serjania lethalis no controle de plantas daninhas. Planta Daninha, Viçosa, v. 31, n. 2, p. 239-248, 2013.

JEFFERSON, L. V.; PENNACHIO, M. Allelopathic effects of foliage extracts from four Chenopodiaceae species on seed germination. Journal of Arid Environments, London, v. 55, p. 275-285, 2003.

LUZ, S. M.; SOUZA FILHO, A. P. S.; GUILOHN, G. M. S. P.; VILHENA, K. S. S. Atividade alelopática de substâncias químicas isoladas da Acacia mangium e suas variações em função do $\mathrm{pH}$. Planta Daninha, Viçosa, v. 28, n. 3, p. 479-487, 2010.

MARASCHIN-SILVA, F.; ÁQUILA, M.E.A. Potencial alelopático de espécies nativas na germinação e crescimento inicial de Lactuca sativa L. (Asteraceae). Acta Botanica Brasilica, Feira de Santana, v. 20, n. 1, p. 61-69, 2006.

MURGU, M.; RODRIGUES-FILHO, E. Dereplication of glycosides from Sapindus saponaria using liquid chromatographymass spectrometry. Journal of the Brazilian Chemical Society, São Paulo, v. 17, n. 7, p. 1281-1290, 2006.

NAPOLITANO, D. R.; MINEO, J. R.; DE SOUZA, M. A.; DE PAULA, J. E.; ESPINDOLA, L. S.; ESPINDOLA, F. S . Downmodulation of nitric oxide production in murine macrophages treated with crude plant extracts from the Brazilian Cerrado. Journal of Ethnopharmacology, Shannon, v. 99, p. 37-41, 2005.

OHARA, S.; OHIRA, T. Plant growth regulation effects of triterpenoid saponins. Journal of Wood Sciences, Kyoto, v. 49, p. 59-64, 2003.

PIMENTEL-GOMES, F. Curso de estatística experimental. 13 ed. Piracicaba: Nobel, 1990. 468 p.

PIRES, E. V. Estudo fitoquímico da espécie Serjania lethalis. 2008. 90 f. Dissertação (Mestrado em Química e Biotecnologia) Universidade Federal de Alagoas, Maceió. 2008.
PITELLI, R. A. Interferência de plantas daninhas em culturas agrícolas. Informe Agropecuário, Belo Horizonte, v. 11, n. 129, p. 16-27, 1985 .

RANAL, M. A.; SANTANA, D. G. How and why to measure the germination process? Revista Brasileira de Botânica, São Paulo, v. 29, n. 1, p. 1-11, 2006.

SILVA, J.; FORTES, A. M. T.; GOMES, F. M.; PINTO, T. T.; BONAMIGO, T.; BOIAGO, N. P. Alelopatia de Camelina sativa Boiss. (Brassicaceae) sobre a germinação e desenvolvimento inicial de Bidens pilosa (L.) e Glycine max (L.) Merr. Biotemas, Florianópolis, v. 24, n. 4, p. 17-24, 2011.

SILVA, P. S. S. Atuação dos aleloquímicos no organismo vegetal e formas de utilização da alelopatia na agronomia. Biotemas, Florianópolis, v. 25, n. 3, p. 65-74, 2012.

SOUZA FILHO, A. P. S.; RODRIGUES, L. R. A.; RODRIGUES, T. J. D. Efeitos de extratos aquosos de assa-peixe sobre a germinação de três espécies de braquiária. Planta Daninha, Viçosa, v. 14, n. 2, p. 93-101, 1996.

SOUZA FILHO, A. P. S.; SANTOS, R. A.; SANTOS, L. S.; GUILHON, G. M. P.; SANTOS, A. S.; ARRUDA, M. S. P.; MULLER, A. H.; ARRUDA, A. C. Potencial alelopático de Myrcia guianensis. Planta Daninha, Viçosa, v. 24, n. 4, p. 649-656, 2006.

TOMAZ, C. A.; MARTINS, C. C.; CARVALHO, L. R. de; NAKAGAWA, J. Duração do teste de germinação do capimtanzânia. Revista Brasileira de Sementes, Londrina v. 32, n. 4, p. 80-87, 2010.

WALLER, G. R.; FEUG, M. C.; FUJII, Y. Biochemical analysis of allelopathic compounds: plants, microorganisms, and soil secondary metabolites. In: INDERJIT, K. M.; DAKSHINI, K. M. M.; FOY, C. L. (Ed.). Principles and practices in plant ecology. Boca Raton: CRC Press, 1999. p. 75-98.

WEIR, T.; PARK, S. W.; VIVIANCO, J. M. Biochemical and physiological mechanisms mediated by allelochemicals. Current Opinion in Plant Biology, London, v. 7, p. 472-479, 2004. 